STORED-ProduCT

\title{
High-Temperature Controlled Atmosphere for Post-Harvest Control of Indian Meal Moth (Lepidoptera: Pyralidae) on Preserved Flowers
}

\author{
JODI A. SAUER AND MARK D. SHELTON \\ California Polytechnic State University, San Luis Obispo, CA 93407
}

\begin{abstract}
J. Econ. Entomol. 95(5): 1074-1078 (2002)
ABSTRACT High carbon dioxide atmospheres combined with high temperature were effective for controlling Indian meal moth, Plodia interpunctella (Hübner) pupae. Pupae were exposed to atmospheres of 60,80 , or $98 \%$ carbon dioxide $\left(\mathrm{CO}_{2}\right)$ in nitrogen $\left(\mathrm{N}_{2}\right)$, or 60 or $80 \% \mathrm{CO}_{2}$ in air at temperatures of $26.7^{\circ} \mathrm{C}$ or $32.2^{\circ} \mathrm{C}$ and $60 \% \mathrm{RH}$. Controlled atmosphere treatments at $32.2^{\circ} \mathrm{C}$ controlled pupae faster than the same treatments at the lower temperature. At both temperatures high $\mathrm{CO}_{2}$ concentration treatments combined with nitrogen killed pupae faster than high $\mathrm{CO}_{2}$ concentration treatments combined with air. Exposure to $80 \%$ carbon dioxide mixed with nitrogen was the most effective treatment causing $100 \%$ mortality in $12 \mathrm{~h}$ at $32.2^{\circ} \mathrm{C}$ and $93.3 \%$ mortality in $18 \mathrm{~h}$ at $26.6^{\circ} \mathrm{C}$. Hightemperature controlled atmosphere treatments had no adverse effects on quality of two preserved floral products, Limonium sinuatum (L.) and Gipsophila elegans (Bieb.), tested for 12, 18, and $24 \mathrm{~h}$ according to industry standards.
\end{abstract}

KEY WORDS Plodia interpunctella, controlled atmosphere, preserved flowers

THE INDIAN MEAL MOTH, Plodia interpunctella (Hübner), is a major pest of stored grains, nuts, dried fruits, and preserved flowers. In California, the Indian meal moth is a considerable problem during processing and storage of dried commodities. The larval stage causes enormous losses by tunneling, feeding, and leaving silk webbing, all of which render stored products unmarketable. The Indian meal moth is the most widely distributed stored product moth (Subramanyam and Hagstrum 1996). The moth's success in infesting stored products is attributed to its ability to obtain nutrients from many different sources and its high reproductive rate in storage conditions.

Indian meal moth commonly infests preserved flowers during commercial storage. These insects must be controlled at the storage plant before they are shipped to consumers. Effective quarantine treatment procedures prevent insect infestations from occuring at flower stores, supermarkets, private houses, or any other flower destinations. The current quarantine treatment for Indian meal moth and other storedproduct pests is methyl bromide fumigation. In 1993, the Environmental Protection Agency classified methyl bromide as an ozone depleter, which will ultimately result in its restricted usage or elimination (UNEP 1992). The high toxicity and safety hazard methyl bromide poses will probably lead to its mandated removal from the list of registered chemicals. As there are few safe and effective chemical substitutes, the trade of dried flowers as well as many other commodities will be severely restricted unless a viable alternative is developed. Controlled atmosphere is a potential fumigant-replacement for controlling pests of stored products and has recently been shown to be effective against Indian meal moth (Johnson et al. 2002).

Controlled atmosphere is a general term used to describe the manipulation of the natural components in air. Air is composed of $\approx 20.9 \%$ oxygen, $0.03 \%$ carbon dioxide, and $79 \%$ nitrogen. To kill insects with controlled atmosphere it is necessary to lower the oxygen content and/or increase the carbon dioxide concentration to toxic levels. Raising the temperature has also been shown to increase the mortality rate of Indian meal moth when exposed to controlled atmosphere (Soderstrom et al, 1986). Our objective was to test the effectiveness of high temperature combined with elevated $\mathrm{CO}_{2}$ atmospheres for controlling Indian meal moth, while maintaining the quality of the preserved flower host.

\section{Materials and Methods}

Insect Rearing Procedure. Indian meal moth colonies obtained from USDA-ARS in Fresno, CA, were originally collected from a walnut packing house in Modesto, CA, on 28 November 1967. Indian meal moths were reared on a modified turkey starter diet (Subramanyam and Cutkomp 1987) at $26.7^{\circ} \mathrm{C}, 60 \%$ RH, and a photoperiod of 14:10 (L:D) $h$.

After $\approx 31 / 2 \mathrm{wk}$, pupae were gently removed from their silk webbing and Indian meal moth diet encasement with two pairs of tweezers. Twenty middle-stage pupae (2-3 d old) were randomly selected and placed 
into each $1 / 2$-pint plastic container labeled with experiment number and treatment code. Any damaged or desiccated pupae in the containers were discarded. The pupal stage was selected for study as it was identified as one of the most tolerant life stages of Indian meal moth to controlled atmosphere-based disinfestation treatments in previous research (Jay 1984, Locatelli and Daolio 1993, Hallman 1994).

Experimental Design. Pupae were exposed to atmosphere treatments for 12,18 , and 24 h at both 26.7 and $32.2^{\circ} \mathrm{C}$. Atmosphere treatments were as follows: $60 \%$ carbon clioxide balanced with nitrogen $(<1.0 \%$ $\left.\mathrm{O}_{2}\right) ; 60 \%$ carbon dioxide mixed with air $\left(8.4 \% \mathrm{O}_{2}\right) ; 80 \%$ carbon dioxide balanced with nitrogen $\left(<1.0 \% \mathrm{O}_{2}\right)$; $80 \%$ carbon dioxide mixed with air $\left(4.2 \% \mathrm{O}_{2}\right) ; 98 \%$ carbon dioxide balanced with nitrogen $\left(<1.0 \% \mathrm{O}_{2}\right)$; and air. Preserved floral products, Gypsophila elegans (Bieb) and Limonium sinuatum (L.) were exposed separately to the same atmospheres and temperatures for 12,18 , and $24 \mathrm{~h}$ to determine if controlled atmosphere and/or high temperature had any adverse effects on quality. All treatment-temperature combinations were replicated three times on preserved flowers and 6-12 times on Indian meal moth pupae.

Indian Meal Moth Experiments. Experiments were conducted in a walk-in environmental chamber (Forma Scientifica, Marietta, $\mathrm{OH}$ ). Different concentrations of gas to establish controlled atmosphere treatments were produced using a mixing board (TransFresh, Salinas, CA) connected to compressed breathing air (Grade D), carbon dioxide (99.9\% purity, A \& R Welding Supply, San Luis Obispo, CA), and nitrogen cylinders. Gases were mixed in a manifold located on the mixing board. A $60-\mathrm{cm}$ water column located on the side of the flow board held a constant barostatic pressure of one psi. The mixed gases flowed through the environmental chamber into separate humidifier jars modified with inflow and outflow septa. These humidifier jars contained a solution of deionized water and glycerol as described by Johnson (1940) to maintain 60\% RH ( $\pm 5 \%$ ). Relative humidity was measured in the humidifier jars immediately before initiation of experiment and measured once every $4 \mathrm{~h}$ and maintained at $60 \%( \pm 5 \%)$ in each treatment bucket throughout each experiment using a digital hygrometer (Certified Traceable Digital Hygrometer/Thermometer, Fisher, Pittsburgh, PA). Capillary tubes supplied 5-gallon treatment buckets with their respective gas treatments from the humidifier jars. Each controlled atmosphere treatment had three buckets and one was removed after 12,18 , and $24 \mathrm{~h}$. Each of the three buckets had the same flow-through gas at $200 \mathrm{ml} / \mathrm{min}$. In each treatment bucket, a onehalf pint modified plastic container with a random sample of 20 pupae was placed. Buckets were air and gas tight to prevent leakage or gas exchange. Atmosphere samples were collected every $4-6 \mathrm{~h}$ through outflow septa in each bucket and analyzed using a gas chromatograph (Tracor 550). Target atmospheres were established inside each treatment bucket $3-4 \mathrm{~h}$ after initiation of gas purging. Carbon dioxide and oxygen concentrations were then maintained within $\pm 5 \%$ of target values. After removal from treatment buckets, pupal containers were held for $14 \mathrm{~d}$ at $26.7^{\circ} \mathrm{C}$ and $60 \% \mathrm{RH}$, and a photoperiod of $14: 10$ (L:D) h. On day 14 the number of emerged adult moths were counted in each container. Any moth body part emerging from the pupal casing was counted as a survivor. Percent mortality was calculated from these data.

Preserved Flower Experiment. The experiment was repeated on preserved flowers using the same high temperature CA treatments for 12, 18, and $24 \mathrm{~h}$. Flowers were fumigated with methyl bromide for insects before experimentation. Gupsophila elegans (Bieb.) was made into $85-\mathrm{g}$ bunches and Limonium sinuatum (L.) was made into $150 \mathrm{~g}$ bunches. Bunches were evaluated for color, brittleness, stem bleeding, and overall quality according to industry standards. One bunch of Gypsophila elegans and one bunch of Limonium sinuatum were placed into each treatment bucket. Upon treatment completion, preserved flowers were transferred to air at room temperature and immediately evaluated. Color change, brittleness, stem bleeding, and overall quality were measured on each bunch in a blind evaluation. Color change for each bunch of preserved flowers was scored a 0 for no obvious color change or a one for obvious color change compared with the color of untreated bunches. Brittleness was initially evaluated by dropping a $1.5 \mathrm{~kg}$ sack filled with flax seed from a height of $30 \mathrm{~cm}$ onto the flower bunches and weighing the broken-off plant parts. This method of evaluation was discontinued after two replications at $32.2^{\circ} \mathrm{C}$ because so few flower parts were detached that it was determined either brittleness was not occurring or our method was ineffective in measuring it. Therefore, another method of evaluating brittleness was used. Brittleness was evaluated by subjecting flowers to extreme handling conditions that simulated industry processing and observing if any flower parts broke off. Each bunch was scored 0 for no brittleness or one for brittleness. Flower bunches were scored one if several broken flower parts were present in the cellophane wrapper. Overall flower quality was rated on a scale of $1-5$, from unmarketable (1) to superior quality (5), both before and after treatment application.

Statistical Analysis. Pupal mortality was determined using the following formula.

$M=$ (no. dead pupae/no. pupae per replication),

where $M=$ mortality rate. Mortality rates were transformed to logits to increase the normality of the data and stabilize variance using the equation.

$$
\text { Logit }=\ln [M /(1-M)] \text {. }
$$

Bartlett's test for homogeneity of variance was used at an alpha level of 0.05 to test the assumption of equal variance on transformed data (MiniTab 1995). Transformed data at 12,18 , and $24 \mathrm{~h}$ had $P$ values of 0.131 , 0.752 , and 1.000 , respectively, indicating stabilized variances. Analysis of variance (ANOVA) was performed using general linear model (GLM) procedure on transformed mortalities at 12,18 , and $24 \mathrm{~h}$ (SAS 
Table 1. Pereent mortality ( \pm SEM) of Indianmeal moth pupae after exposure to high-ternperature controlled atmosphere and air at $60 \% \mathrm{RH}$

\begin{tabular}{|c|c|c|c|c|}
\hline \multirow{2}{*}{ Atmosphere } & \multirow{2}{*}{ Temp, ${ }^{\circ} \mathrm{C}$} & \multicolumn{3}{|c|}{$\%$ mortality } \\
\hline & & 12 & 18 & 24 \\
\hline
\end{tabular}

Differences in percent mortality values were determined on the logit scale using GLM. Percent mortalities \pm SEM within columns having the same letter are not significantly different $(P>0.05)$ by Duncan's multiple range test.

"Time measured from initiation of the atmosphere in treatment containers.

Institute 1985). Separate analyses were used for each time interval. Percent mortality and standard error for the mean were determined for each treatment at each time interval using the linear model:

$$
\text { Logit }=\beta_{0}+\beta_{1}(\text { treatment })+v,
$$

where treatment is the high-temperature atmosphere combination and $v$ is the error term. Duncan multiple range test (SAS Institute 1985) was used to locate significant treatment effects.

\section{Results}

Indian Meal Moth Experiments. Percent mortality for each controlled atmosphere treatment is compared in Table 1.

Longer exposure to high-temperature controlled atmosphere resulted in reduced adult emergence. Increasing exposure time from 12 to $18 \mathrm{~h}$ greatly reduced survival of Indian meal moth pupae treated with $80 \%$ $\mathrm{CO}_{2}$ and low oxygen compared with the other high $\mathrm{CO}_{2}$ treatments at $26.7^{\circ} \mathrm{C}$. Atmospheres combining elevated carbon dioxide and low oxygen concentrations killed insects significantly faster than high $\mathrm{CO}_{2}$ concentrations combined with air after $18(F=30.23$, $\mathrm{df}=11, P<0.0001)$ and $24 \mathrm{~h}$ at $26.6^{\circ} \mathrm{C}(F=49.67, \mathrm{df}=$ $11, P<0.0001$ ) (Table 1). Atmospheres combining $60 \% \mathrm{CO}_{2}$ and air were not effective at controlling Indian meal moth at $26.6^{\circ} \mathrm{C}$. After $24 \mathrm{~h}$, both 60 and $80 \%$ $\mathrm{CO}_{2}$ atmospheres combined with low oxygen caused $100 \%$ mortality at $26.7^{\circ} \mathrm{C}$. Other treatments failed to completely kill Indian meal moth pupae after $24 \mathrm{~h}$ at $26.7^{\circ} \mathrm{C}$.

As temperature increased, the mortality rate of Indian meal moth under controlled atmosphere also increased (Table 1). Combining high carbon dioxide with low oxygen at $32.2^{\circ} \mathrm{C}$ for $12 \mathrm{~h}$ caused significantly greater mortality compared with the same atmospheres at $26.7^{\circ} \mathrm{C}(F=18.22, \mathrm{df}=11, P<0.0001)$. Treatments consisting of high $\mathrm{CO}_{2}$ combined with low oxygen did not differ significantly after $12 \mathrm{~h}$ at $32.2^{\circ} \mathrm{C}$
( $F=30.23, \mathrm{df}=11, P<0.0001)$. Time required to cause $100 \%$ mortality for Indian meal moth pupae was $12 \mathrm{~h}$ at $32.2^{\circ} \mathrm{C}$ using $80 \%$ carbon dioxide and $<1.0 \%$ oxygen. Atmospheres with reduced oxygen levels required less time to kill Indian meal moth pupae compared with atmospheres mixed with air after $12 \mathrm{~h}$ at $32.2^{\circ} \mathrm{C}(P<0.0001)$. Insect mortality after exposure to 60,80 , or $98 \% \mathrm{CO}_{2}$ combined with low oxygen at $32.2^{\circ} \mathrm{C}$ for $18 \mathrm{~h}$ was significantly greater than mortality resulting from exposure to $60 \% \mathrm{CO}_{2}$ combined with air $(F=30.23, \mathrm{df}=11, P<0.0001)$. Although, all high carbon dioxide treatments appeared equally effective in controlling Indian meal moth pupae after $24 \mathrm{~h}$ at $32.2^{\circ} \mathrm{C}$.

Preserved Flower Experiment. Flowers of Limonium sinuatum and Gypsophila elegans did not decline in quality when subjected to high temperature controlled atmosphere treatments. No significant differences in brittleness, color, stem bleeding, or quality were observed in response to controlled atmosphere treatments when both varieties of preserved flowers were evaluated before and after exposure to treatments (data not shown). All flowers were scored 0 after treatment for brittleness, color, and stem bleeding, indicating no observable changes in the flowers for these factors. Before and after treatment, all preserved flowers were scored 5 for superior quality. Preserved flowers subjected to high-temperature alone were not visibly different than preserved flowers subjected to high-temperature controlled atmosphere for 12,18 , and $24 \mathrm{~h}$. High-temperature controlled atmosphere does not appear to affect the marketability of either flower species.

\section{Discussion}

Stored-product insects have been successfully controlled with low oxygen or high carbon dioxide atmospheres (Jay 1984, Hallman 1994, Johnson et al. 2002). High temperature combined with high carbon dioxide is a viable alternative to methyl bromide fumigation of 
preserved flowers, grains, nuts, dried fruits, and other stored products. Controlled atmosphere treatment must control Indian meal moth and other stored-product insects on preserved and dried flowers to be commercially viable for dried flower producers. As expected, higher temperatures and lower oxygen levels reduced the exposure time required to kill Indian meal moth. High temperature $\left(32.2^{\circ} \mathrm{C}\right)$ combined with high levels of $\mathrm{CO}_{2}\left(80 \% \mathrm{CO}_{2}\right)$ and low oxygen $\left(<1.0 \% \mathrm{O}_{2}\right)$ was the most effective treatment for controlling Indian meal moth. However, maintaining low oxygen concentration is difficult and expensive in part due to the difficulty in controlling gas leak rates in fumigation and intermodal shipping containers (Jay 1984, Shelton et al. 1996). Treatments using $80 \% \mathrm{CO}_{2}$ mixed with air at $32.2^{\circ} \mathrm{C}$ controlled Indian meal moth in $24 \mathrm{~h}$ as compared with only $12 \mathrm{~h}$ needed to cause $100 \%$ mortality using $80 \% \mathrm{CO}_{2}$ combined with low oxygen.

Using a combination treatment of high temperature and high $\mathrm{CO}_{2}$ increases the sensitivity of Indian meal moth to CA treatment. Our work and previous research indicates that raising the temperature increases the insecticidal effect of controlled atmosphere against Indian meal moth (Jay 1984, Locatelli and Daolio 1993). At high temperatures, insects respire faster causing the spiracles to open wider so the insect can take in more oxygen (Nicolas and Sillans 1989, Locatelli and Daolio 1993). Reducing the oxygen concentration while elevating the $\mathrm{CO}_{2}$ concentration reduces the time necessary to kill Indian meal moth. Our results with Indian meal moth pupae support the findings of previous studies on other stored product insect pests demonstrating that simultaneously combining high temperature, high $\mathrm{CO}_{2}$, and low oxygen has a greater effect on mortality than any single factor alone (Hallman 1994).

The tolerance of preserved flowers to high temperature treatments was a concern for developing a practical controlled atmosphere treatment. Temperatures as high as $32.2^{\circ} \mathrm{C}$ combined with controlled atmosphere did not affect the quality of tested flowers. Higher temperatures were not tested because of the difficulty of raising commercial treatment chambers above $32.2^{\circ} \mathrm{C}$. If temperatures were increased above $32,2^{\circ} \mathrm{C}$, control of Indian meal moth could likely be achieved in less than $12 \mathrm{~h}$ using elevated levels of $\mathrm{CO}_{2}$ combined with low oxygen levels. In addition, the time required for $100 \%$ mortality can likely be further reduced by lowering the relative humidity below $60 \%$ (Soderstrom et al. 1986).

Tests were conducted on pupae, but results will likely differ for other Indian meal moth life stages. We used Indian meal moth strains reared under laboratory conditions since 1967 in our study. Studies by Johnson et al. (1995) indicated that Indian meal moth developmental rate, survival, and reproduction vary depending on diet, and whether colonies were feral or cultured. Differences between laboratory reared isolates and wild-type isolates may affect the efficacy of controlled atmosphere treatments.

Trials were conducted on a small number of insects without the storage product present and commercial results might be different. Additional experiments should be conducted on preserved flowers infested with high levels of Indian meal moth to test the efficacy of the high-temperature controlled atmosphere treatments. The effect of high-temperature controlled atmosphere treatments on other pests such as the tobacco moth, Ephestia elutella (Hübner), the angoumois grain moth, Sitotroga cerealella (Olivier), and the rice weevil, Sitophilus oryzae (L.), that commonly infest preserved flowers, should also be evaluated.

High $\mathrm{CO}_{2}$ atmospheres successfully control Indian meal moth in $24 \mathrm{~h}$ or less at $32.2^{\circ} \mathrm{C}$. Pupae of Indian meal moth were most susceptible to high $\mathrm{CO}_{2}$ and low $\mathrm{O}_{2}$ treatments at $32.2^{\circ} \mathrm{C}$. As expected, present and previous research indicates that insects are killed faster with controlled atmospheres at higher temperatures (Jay 1984, Soderstrom et al. 1986, Locatelli and Daolio 1993). Flower susceptibility to high temperature was also a factor in choosing test temperatures.

It is imperative to find a practical and viable alternative to methyl bromide, before the agricultural industry suffers from its loss. Controlled atmosphere treatment is gaining more attention in the stored product industry as an economically feasible substitute for chemical fumigation. Controlled atmosphere used for insect disinfestation is safe, practical, and leaves no undesirable chemical residue on products. Future effort should focus on developing controlled atmosphere systems to employ optimum high-temperature controlled atmosphere treatments to be used commercially by the dried flower industry to control stored-product insect pests that infest dried and preserved commodities.

\section{Acknowledgments}

We express our gratitude to all those who were generous with their time on this project. Thanks to ScottSteinmaus and Heather Smith (Cal Poly) for their statistical advice, Shirley May (USDA, Fresno, CA) for providing the insects, to 3-Way Farms for contributing the flowers, and to TransFresh Corporation for donating much of the equipment used in this study.

\section{References Cited}

Hallman, G. J. 1994. Controlled atmospheres, pp. 121-133. In R. E. Paull and J. W. Armstrong (eds.), Insect pests and fresh horticultural products: treatments and responses. $\mathrm{CAB}$, Wallingford, UK.

Jay, E. 1984. Imperfections in our current knowledge in insects biology as related to their response to controlled atmosphere, pp. 103-104, In Controlled atmosphere and fumigation in grain storages. Elsevier, Amsterdam.

Johnson, C. G. 1940. The maintenance of high atmospheric humidities for entomological work with glycerol-water mixtures. Ann. Appl. Biol. 27: 295-299.

Johnson, J. A., P. V. Vail, D. G. Brandl, J. S. Tebbets, and K. A. Valero. 2002. Integration of nonchemical treatments for control of postharvest pyralid moths (Lepidoptera: Pyralidae) in almonds and raisins. J. Econ. Entomol. 95: 190-199. 
Johnson, J. A., P. L. Wofford, and R. F. Gill. 1995. Developmental thresholds and degree-day accumulations of Indian meal moth (Lepidoptera: Pyralidae) on dried fruits and nuts. J. Econ. Entomol. 88: 734-742.

Locatelli, D.P., and E. Daolio. 1993. Effectiveness of carbon dioxide under reduced pressure against some insects infesting packaged rice. J. Stored Prod. Res, 29: 81-87.

Minitab. 1995. Minitab user's guide. Minitab, State College, PA.

Nicolas, $G_{\text {. }}$ and D. Sillans. 1989. Immediate and latent effects of carbon dioxide on insects. Annu. Rev. Entomol. 34: 97-116.

SAS Institute. 1985. SAS introductory guide, 3rd ed. SAS Institute, Cary, NC.

Shelton, M., V. Walter, D. Brandl, and V. Mendez. 1996. The effects of refrigerated, controlled atmosphere storage during marine shipment on insect mortality and cutflower vase life. HortTechnology 6: 247-250.
Soderstrom, E. L., B. E. Mackey, and D. G. Brandl. 1986 Interactive effects of low-oxygen atmospheres, relative humidity, and temperature on mortality of two storedproduct moths (Lepidoptera: Pyralidae). J. Econ. Entomol. 79: 1303-1306.

Subramanyam, B, and D. Cutkomp. 1987. Total lipid and fatty acid composition in male and female larvae of Indian meal moth and almond moth. (Lepidoptera: Pyralidae). Gt. Lakes Entomol. 20: 99-102.

Subramanyam, B., and D. W. Hagstrum. 1996. Integrated management of insects in stored products. Marcel Dekker, New York.

UNEP. 1992. Fourth meeting of the parties to the Montreal Protocol on substances that deplete the ozone layer, Copenhagan, 23-25 November 1992. United Nations Environmental Programme, New York.

Received for publication 30 August 2000; accepted 5 April 2002. 